\title{
Factors Affecting Pseudomonas savastanoi pv. savastanoi Plant Inoculations and Their Use for Evaluation of Olive Cultivar Susceptibility
}

\author{
R. Penyalver, A. García, A. Ferrer, E. Bertolini, J. M. Quesada, C. I. Salcedo, J. Piquer, \\ J. Pérez-Panadés, E. A. Carbonell, C. del Río, J. M. Caballero, and M. M. López
}

First, second, third, fourth, fifth, sixth, seventh, and twelfth authors: Departamento de Protección Vegetal y Biotecnología, Instituto Valenciano de Investigaciones Agrarias (IVIA), Apartado Oficial, 46113 Moncada, Valencia, Spain; eighth and ninth authors: Unidad de Biometría, IVIA, Apartado Oficial, 46113 Moncada, Valencia, Spain; and tenth and eleventh authors: Área de Mejora y Biotecnología, Centro de Investigación y Formación Agraria (CIFA) “Alameda del Obispo” (IFAPA), Apartado 3092, 14008 Córdoba, Spain. Accepted for publication 23 November 2005.

\begin{abstract}
Penyalver, R., García, A., Ferrer, A., Bertolini, E., Quesada, J. M., Salcedo, C. I., Piquer, J., Pérez-Panadés, J., Carbonell, E. A., del Río, C., Caballero, J. M., and López, M. M. 2006. Factors affecting Pseudomonas savastanoi pv. savastanoi plant inoculations and their use for evaluation of olive cultivar susceptibility. Phytopathology 96:313-319.

Pseudomonas savastanoi pv. savastanoi causes olive knot disease, which is present in most countries where olive trees are grown. Although the use of cultivars with low susceptibility may be one of the most appropriate methods of disease control, little information is available from inoculation assays, and cultivar susceptibility assessments have been

savastanoi strains evaluated were highly virulent to olive plants, but interactions between cultivars and strains were found. The severity of the disease in a given cultivar was strongly dependent of the pathogen dose applied at the wound sites. Secondary tumors developed in noninoculated wounds following inoculation at another position on the stem, suggesting the migration of the pathogen within olive plants. Proportion and weight of primary knots and the presence of secondary knots were evaluated in 29 olive cultivars inoculated with two pathogen strains at two inoculum doses, allowing us to rate most of the cultivars as having either high, medium, or low susceptibility to olive knot disease. None of the cultivars were immune to the disease.
\end{abstract} limited to few cultivars. We have evaluated the effects of pathogen virulence, plant age, the dose/response relationship, and the induction of secondary tumors in olive inoculation assays. Most $P$. savastanoi pv.
Additional keywords: Olea europaea, olive germplasm bank, resistance.
Olive knot disease, caused by the bacterium Pseudomonas savastanoi pv. savastanoi, seriously affects olive trees (Olea europaea L.) mainly in Mediterranean countries, where climatic conditions often favor spread of the disease. Disease symptoms are characterized by tumorous outgrowths on different parts of infected plants, mainly shoots and branches. The development of these galls is dependent on bacterial production of the phytohormone indoleacetic acid and cytokinins $(5,13,19,21)$, and more recently it has been reported that olive knot formation is $\mathrm{hrp} / \mathrm{hrc}$ dependent (17).

Nowadays there is an increasing interest in olive-growing in many countries probably due to the benefits of olive oil for human health $(1,14)$. Spain is the leading world producer of olive oil with about 2.5 million ha of olive trees, representing about $25 \%$ of the world's cultivated area and producing almost $50 \%$ of the world's olive oil production. Olive knot disease is considered an important problem for olive crops because of its effect on vegetative growth (24), olive yield (16), and even possibly on olive oil quality (15).

The use of resistant cultivars is considered one of the most appropriate methods of control, but unfortunately, little information is available from comparative inoculation experiments and is limited to a few cultivars from Italy, Morocco, and Portugal (3,9, 11,23). Information also comes from field observations such as those reported in Spain $(2,22)$. Because evaluation of germplasm for olive knot susceptibility has been very limited, little is known

Corresponding author: M. M. López; E-mail address: mlopez@ivia.es

DOI: 10.1094/PHYTO-96-0313

(C) 2006 The American Phytopathological Society about the occurrence of resistance (18), and germplasm assessment is the first step toward determining the feasibility of breeding for olive knot resistance. Therefore, the aim of this study was to analyze factors affecting $P$. savastanoi pv. savastanoi inoculations, such as pathogen virulence, dose/response behavior, plant age, and secondary tumor development, in order to assess cultivar susceptibility. The methodology developed was applied to the evaluation of 29 olive cultivars, mainly from the World Olive Germplasm Bank, Centro de Investigación y Formación Agraria (CIFA) "Alameda del Obispo," Córdoba, Spain, for resistance to olive knot disease.

\section{MATERIALS AND METHODS}

Bacterial strains and inoculum preparation. Twenty Spanish strains of $P$. savastanoi pv. savastanoi isolated from olive knots were obtained from the Instituto Valenciano de Investigaciones Agrarias (IVIA) collection, and the type strain CFBP $1670^{\mathrm{T}}$ was obtained from the Collection Française de Bactéries Phytopathogènes (CFBP), INRA, Angers, France, as supplied by L. Gardan. Strains were routinely grown in King's medium B (10) at $26^{\circ} \mathrm{C}$. Bacterial suspensions for plant inoculations were adjusted turbidometrically to densities of ca. $10^{8}$ colony forming units (CFU) per $\mathrm{ml}$ (optical density at $600 \mathrm{~nm}=0.5$ ) in phosphate buffered saline (PBS) and 10-fold dilutions in PBS were prepared when appropriate.

Plant material. One- and three-year-old olive plants from the World Olive Germplasm Bank of Spain were used (6). Plants were propagated by rooting soft-wood cuttings under mist (4), and the rooted cuttings were planted in plastic pots as single trunk trees by removing other shoots when their average height was 
around 25 to $40 \mathrm{~cm}$ (7). After inoculation, plants were kept in the open-air inside a screenhouse in individual pots filled with a substrate composed of peat and sand (1:0.6, vol/vol) and watered by trickle irrigation.

Virulence of $\boldsymbol{P}$. savastanoi pv. savastanoi strains. One-yearold plants of cvs. Arbequina, Blanqueta, Borriolenca, Manzanilla, Picual, and Villalonga were used to select the P. savastanoi pv. savastanoi strains for further experiments. Olive plants were wounded at three sites on the main stem and at two sites on lateral branches. Wounds of $0.5 \mathrm{~cm}$ long from the stem surface into the cambial area were made with a sterile scalpel. Each wound site was inoculated with $10^{6} \mathrm{CFU}$ of $P$. savastanoi pv. savastanoi in $10-\mu l$ aliquots of PBS. Two plants of each cultivar were used for each of the 21 assayed strains (60 wound sites per strain). Another two plants were used as noninoculated control plants. The number of inoculated wound sites developing knots was recorded 3 months after inoculations.

Dose/response relationship. Olive plants of cvs. Nevadillo blanco de Jaén-cj, Lechín de Sevilla, and Mollar de Cieza were wounded at 10 sites on the main stem as described previously. Increasing 10-fold doses of $P$. savastanoi pv. savastanoi strain IVIA 1628 from ca. 10 to $10^{6} \mathrm{CFU}$ were applied to wounds in $5-\mu l$ aliquots of PBS. Five to ten plants were inoculated per dose (50 to 100 wound sites per dose) in two independent experiments. Two plants were used as noninoculated control plants. The disease response for each dose was measured as the proportion of inoculated wound sites developing knots 3 months after inoculations.

Effect of plant age. One- and three-year-old olive plants of cvs. Callosina, Dulzal de Carmona-cj, Nevadillo blanco de Jáencj, Picual, and Picudo were compared for olive knot reaction. Plants were wounded at four sites on the main stem and inoculated with $P$. savastanoi pv. savastanoi strains IVIA 1628 and IVIA $1657-8$ at low $\left(10^{2} \mathrm{CFU} /\right.$ wound $)$ and high $\left(10^{6} \mathrm{CFU} /\right.$ wound $)$ doses. Eleven plants of each cultivar were used per strain at each dose (44 inoculation sites per dose and strain). The disease reaction was measured as described previously.

Secondary knots. One-year-old olive plants of cvs. Lechín de Granada, Gordal sevillana, and Picual and 3-year-old plants of cvs. Callosina, Cornicabra, Dulzal de Carmona, and Nevadillo blanco de Jaén-cj were wounded at one site on the main stem, $10 \mathrm{~cm}$ above the crown. The initial wounds (wound site number 1, Fig. 1) were inoculated with $P$. savastanoi pv. savastanoi strains IVIA 1628 or IVIA $1657-8$ at a high inoculum dose $\left(10^{6} \mathrm{CFU} /\right.$

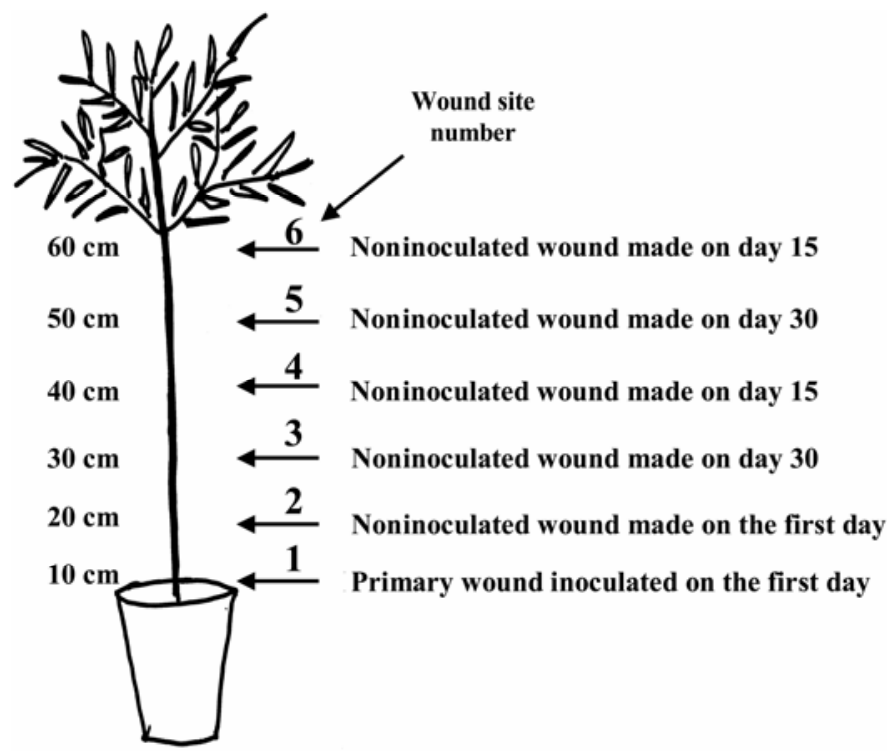

Fig. 1. Diagram showing the position and time of wounding for the secondary knots assay. wound). On the same inoculation day, another wound (site number 2) was aseptically made on the main stem, $10 \mathrm{~cm}$ from the initial wound site ( $20 \mathrm{~cm}$ above the crown), but was not inoculated (Fig. 1). Fifteen days after inoculation of the initial wound, two new wounds were made 40 and $60 \mathrm{~cm}$ above the crown (site numbers 4 and 6), but were not inoculated. Thirty days after inoculation of the initial wound, two new wounds were made 30 and $50 \mathrm{~cm}$ above the crown (site numbers 3 and 5), but were not inoculated (Fig. 1). Eight to thirteen replicate plants of each cultivar were used per strain. Two plants per strain and cultivar were used as noninoculated control plants. The number of noninoculated wound sites developing knots was recorded 3 months after each wounding.

Cultivar susceptibility. Twenty-six olive cultivars were used for the evaluation of the development and weight of primary knots and the presence of secondary knots after inoculations with $P$. savastanoi pv. savastanoi. Two-year-old plants were wounded at five sites on the main stem and inoculated with $P$. savastanoi pv. savastanoi strains IVIA 1628 and IVIA 1657-8 with low $\left(10^{2} \mathrm{CFU} /\right.$ wound $)$ and high $\left(10^{6} \mathrm{CFU} /\right.$ wound $)$ inoculum doses. Ten plants per cultivar, strain, and dose were used (50 inoculation sites per dose and strain with each cultivar). All inoculations were performed in late spring. Two to four plants of each cultivar were inoculated with buffer as control plants. The disease response was measured as described above 3 months after inoculations. The next spring, knots were removed and weighted. Five new wounds between the previous ones were aseptically made in order to evaluate the appearance of secondary knots 3 months after wounding. Two independent experiments were done, one for the evaluation of 16 cultivars in 1999 and a second one in 2001 with 25 cultivars, including 12 replicate cultivars already analyzed in the previous experiment, in order to evaluate the reproducibility of the analyses.

Each cultivar included in the susceptibility analysis was rated with respect to the development and weight of primary knots and the presence of secondary knots. In each experiment, a given cultivar was considered as having high susceptibility for the production of primary and secondary knots when in a given treatment the percentage of wounds developing knots showed no significant differences with the highest obtained value. On the other hand, a given cultivar was considered as having low susceptibility when the percentage of knots showed no significant differences with the smallest obtained value. A given cultivar was considered as having medium susceptibility when the percentage of knots fell in the middle of the previous two groups. Cultivars were also rated according to the average weight of knots per diseased plant, in three categories: high, medium, and low susceptibility, considering medium as those cultivars with no significant differences with the average value.

Statistical analysis. For the selection of the most appropriate inoculum dose, the standard error of the probability that an inoculated wound develops a knot was obtained using the normal approximation after the formula

$$
\sigma_{\hat{p}}=\sqrt{\frac{\hat{p}(1-\hat{p})}{n}}
$$

For cultivar susceptibility, two different approaches were used according to the type of distribution of the variable. For the percentage of wounds developing knots and secondary knots, a twoway generalized linear model (12) assuming binomial distribution was used. All possible contrasts were calculated to compare means. When an interaction was significant, the analyses were done individually for each strain. In all cases, due to the high number of mean comparisons, the Bonferroni correction was used to maintain the type I error to nominal 5\% levels although the power of the test was very low. In order to know if there was a relationship between the number of inoculated wound sites developing knots and the number of knots that appeared in the non- 
inoculated wound sites, a Spearman correlation test was calculated for each combination of assay, dose, and strain. For the average weight of knots, a two-way analysis of variance (strain by cultivar) within each experiment and dose was performed. Mean comparisons were obtained by the DGC test (8) that allows a disjoint classification of the means.

\section{RESULTS}

Virulence of $\boldsymbol{P}$. savastanoi pv. savastanoi strains. Differences in virulence among $21 P$. savastanoi pv. savastanoi strains were investigated in order to select representative strains for further cultivar susceptibility analyses. Two strains, CFBP $1670^{\mathrm{T}}$ and a Spanish strain, were less virulent than the others, causing knots only in 25 and $6.6 \%$ of inoculated wound sites, respectively. Two other strains were intermediate in virulence (62 and $55 \%$ of inoculations developing knots, respectively). The other 17 strains were highly virulent, producing knots in more than $80 \%$ of the inoculated wounds. These strains caused symptoms in all inoculated cultivars, except one strain that did not cause knot formation in one cultivar. None of control plants developed knots at any wound site. Two of the highly virulent strains (IVIA 1628 and IVIA 1657-8) were considered representative of the majority of Spanish strains and they were selected for further use.

Dose/response relationship. Six levels of inocula were applied to olive plants to determine the optimum doses for symptom development and evaluation of cultivar susceptibility. For a given cultivar, the disease response (measured as the probability that an inoculated wound develop a knot) was strongly dependent on the inoculum dose applied (Fig. 2). At the highest inoculum dose $\left(10^{6} \mathrm{CFU} /\right.$ wound) almost all inoculation sites developed knots in the three cultivars assayed. The disease response decreased with decreasing amounts of bacteria applied to each wound site. As is shown in Figure 2, the greatest difference between cultivars was found after inoculating $10^{2} \mathrm{CFU} /$ wound. None of control plants produced knots in any wound site. Thus, we selected the inoculum dose of $10^{2} \mathrm{CFU} /$ wound for the susceptibility analysis of cultivars. A high inoculum dose $\left(10^{6} \mathrm{CFU} /\right.$ wound $)$ was also included in the analysis as a positive control, in order to identify low susceptible cultivars.

Effect of plant age. Preliminary inoculation experiments performed on 1-year-old plants indicated that the assayed cultivars were all highly susceptible (data not shown), and then the disease response for 1- and 3-year-old plants was compared. After inocu-

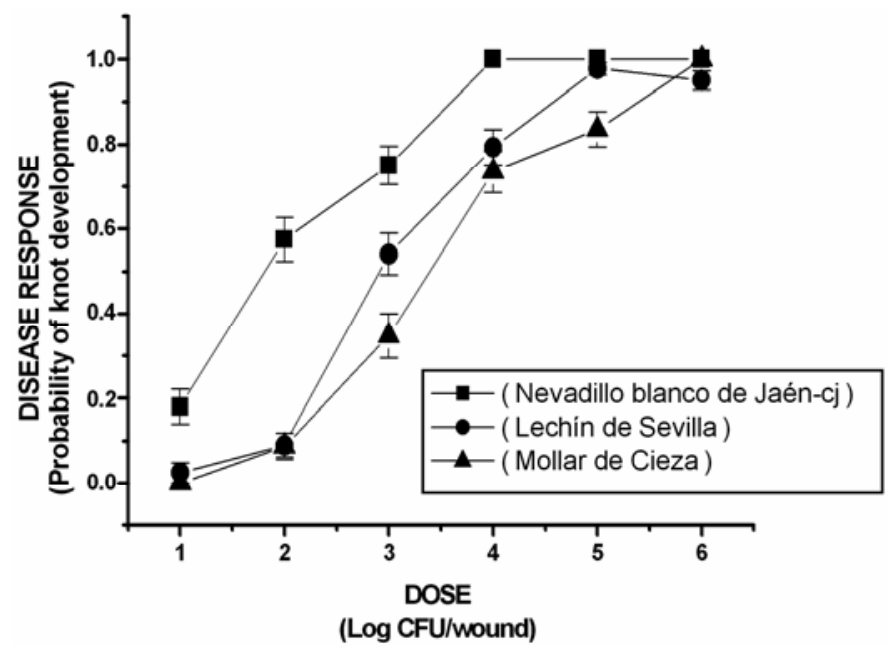

Fig. 2. Dose/response effect for three olive cultivars after inoculation with different concentrations of Pseudomonas savastanoi pv. savastanoi strain IVIA 1628. Data represent the probability that a wound site develops a knot based on 50 to 100 inoculated wound sites from two independent experiments. Bars represent the standard error. lation with the high dose of bacteria $\left(10^{6} \mathrm{CFU} /\right.$ wound $)$, the percentage of inoculated sites developing knots was greater than 80 and $60 \%$ using 1- and 3-year-old plants, respectively, in all cultivars inoculated with both $P$. savastanoi pv. savastanoi strains. However, when inoculating with the low dose of bacteria $\left(10^{2} \mathrm{CFU} /\right.$ wound), a different reaction between 1 - and 3-year-old plants was observed for some cultivars (Fig. 3). One-year-old plants developed knots in more than $80 \%$ of inoculated wounds, precluding the differentiation of cultivar susceptibility. However, when 3-year-old plants were inoculated with the low inoculum dose, the proportion of wounds developing knots ranged from 25 to $98 \%$ depending on the cultivar, allowing us to establish different susceptibility groups. Consequently, 1-year-old plants were not used in further cultivar susceptibility experiments.

Secondary knots. After wound inoculation with $P$. savastanoi pv. savastanoi at one position on olive stems, secondary tumors developed in new wounds subsequently performed away from the primary inoculation site, and the frequency of the appearance of the secondary knots varied among cultivars and strains (Table 1). Noninoculated control plants did not produce any knot in the preformed wounds. P. savastanoi pv. savastanoi migrated and produced secondary knots more easily on cvs. Picual and Gordal sevillana than on other cultivars. On Picual, 17 noninoculated wound sites developed secondary knots with the following distribution: 10 knots developed on wounds made on the first day (10 $\mathrm{cm}$ from primary knots), three knots developed on wounds made on day 15 (30 cm from primary knots), and four knots developed on wounds made on day $30(20 \mathrm{~cm}$ from primary knots). Secondary tumors did not appear further than $40 \mathrm{~cm}$ from the primary inoculation site. On Gordal sevillana, 16 noninoculated wound sites developed secondary knots with the following distribution: eight knots developed on wounds made on the first day, five knots developed on wounds made on day 15, and three knots developed on wounds made on day 30 . Two knots developed in noninoculated wounds $50 \mathrm{~cm}$ from the primary inoculation site. The rest of the cultivars developed between two and four secondary knots. On Cornicabra, secondary knots were not produced with either strain.

Cultivar susceptibility. The development and weight of primary knots and the presence of secondary knots were evaluated after inoculations with $P$. savastanoi pv. savastanoi in 29 olive cultivars in two experiments. In the first experiment, 16 olive cultivars were evaluated (Table 2). As expected, when using a high inoculum dose, all cultivars, except one, developed knots at more than $90 \%$ of inoculation sites, and no significant differences were observed between the two $P$. savastanoi pv. savastanoi strains used as inoculum (data not shown). However, when inoculating with a low dosage inoculum, we found large differences in disease response among cultivars using both pathogen strains. The percent-

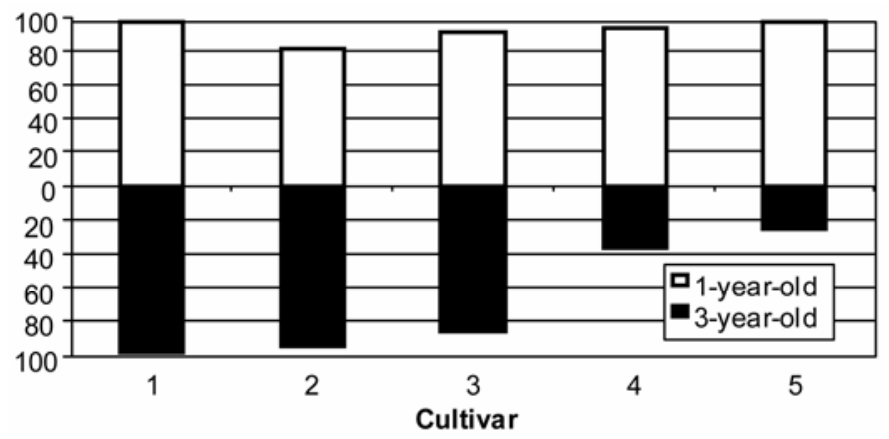

Fig. 3. Percentages of inoculated wound sites developing knots in 1- and 3-year-old plants of five olive cultivars inoculated with the pathogen strain IVIA 1628 at $10^{2}$ bacteria per wound. Cultivars were as follows: 1, Callosina; 2, Picudo; 3, Nevadillo blanco de Jaén-cj; 4, Dulzal de Carmona-cj; and 5, Picual. 
age of inoculated sites developing knots ranged from 0 to $100 \%$ depending on the cultivar (Table 2). None of control plants produced knots in any wound site. Mean values of the average weight of knots per diseased plant on each cultivar inoculated with both $P$. savastanoi pv. savastanoi strains at the low inoculum dose are also shown in Table 2. Six cultivars produced an average weight of knots per diseased plant significantly larger than the average of all cultivars $(\bar{x}=0.33)$. Significant differences in the presence of secondary knots were found among cultivars after inoculating the primary wound sites with a low inoculum dose of either $P$. savastanoi pv. savastanoi strain (Table 2). The percentages of noninoculated sites developing knots ranged from 0 to $86 \%$ depending on the cultivar. A positive correlation was found between the number of primary and secondary knots inoculated with either $P$. savastanoi pv. savastanoi strain.

In the second experiment, 25 olive cultivars were evaluated, including 12 cultivars already analyzed in the first experiment (Table 3). When inoculating with low dose inoculum, we found again significant differences in disease response with both challenge pathogens. The percentages of inoculated sites developing knots ranged from 0 to $100 \%$, allowing us to make a rating of cultivars as shown below. None of the control plants produced knots in any wound site. Only cvs. Frantoio, Koroneiki, and Oblonga produced an average weight of knots per diseased plant significantly greater than the average of all cultivars $(\bar{x}=0.58)$. With respect to the presence of secondary knots in noninoculated wound sites, differences among the cultivars were found only when inoculating the initial wound sites with high dose inoculum using strain IVIA 1628. Noninoculated sites developed knots at rates of 0 to $65.5 \%$, depending on the cultivar (data not shown).

Each cultivar evaluated in both performed experiments was rated for the development and weight of primary knots and the presence of secondary knots in each experiment using the low inoculum dose (Table 4). Considering the development of primary knots as the main factor to assess cultivar susceptibility, cv.

TABLE 1 . Number of secondary knots appearing at wound sites 3 months after each wounding

\begin{tabular}{|c|c|c|c|c|c|c|c|c|c|}
\hline \multirow[b]{2}{*}{ Cultivar } & \multirow{2}{*}{$\begin{array}{l}\text { Pseudomonas savastanoi } \\
\text { pv. savastanoi } \text { strain }\end{array}$} & \multirow{2}{*}{$\begin{array}{l}\text { No. of plants } \\
\text { inoculated }\end{array}$} & \multicolumn{6}{|c|}{$\begin{array}{l}\text { No. of primary (1) and secondary knots } \\
\text { at different wound locations }(2 \text { to } 6)^{\mathrm{z}}\end{array}$} & \multirow{2}{*}{$\begin{array}{c}\text { Total no. of } \\
\text { secondary knots }\end{array}$} \\
\hline & & & 1 & 2 & 3 & 4 & 5 & 6 & \\
\hline \multirow[t]{2}{*}{ Picual } & IVIA 1628 & 12 & 12 & 4 & 2 & 1 & 0 & 0 & 7 \\
\hline & IVIA $1657-8$ & 11 & 11 & 6 & 2 & 2 & 0 & 0 & 10 \\
\hline \multirow[t]{2}{*}{ Gordal sevillana } & IVIA 1628 & 8 & 8 & 2 & 0 & 0 & 0 & 0 & 2 \\
\hline & IVIA $1657-8$ & 13 & 13 & 6 & 3 & 3 & 0 & 2 & 14 \\
\hline \multirow[t]{2}{*}{ Nevadillo blanco de Jaén-cj } & IVIA 1628 & 13 & 13 & 0 & 0 & 0 & 0 & 0 & 0 \\
\hline & IVIA $1657-8$ & 13 & 12 & 2 & 1 & 1 & 0 & 0 & 4 \\
\hline \multirow[t]{2}{*}{ Lechín de Granada } & IVIA 1628 & 13 & 13 & 1 & 0 & 0 & 0 & 0 & 1 \\
\hline & IVIA $1657-8$ & 12 & 12 & 1 & 0 & 1 & 0 & 0 & 2 \\
\hline \multirow[t]{2}{*}{ Dulzal de Carmona } & IVIA 1628 & 12 & 11 & 1 & 1 & 0 & 0 & 1 & 3 \\
\hline & IVIA $1657-8$ & 13 & 13 & 0 & 0 & 0 & 0 & 0 & 0 \\
\hline \multirow[t]{2}{*}{ Callosina } & IVIA 1628 & 13 & 13 & 1 & 0 & 0 & 0 & 0 & 1 \\
\hline & IVIA $1657-8$ & 13 & 12 & 1 & 0 & 0 & 0 & 0 & 1 \\
\hline \multirow[t]{2}{*}{ Cornicabra } & IVIA 1628 & 13 & 9 & 0 & 0 & 0 & 0 & 0 & 0 \\
\hline & IVIA $1657-8$ & 13 & 13 & 0 & 0 & 0 & 0 & 0 & 0 \\
\hline
\end{tabular}

y Two plants per strain and cultivar were used as noninoculated control plants. None of those control plants produced knots in any wound site.

${ }^{\mathrm{z}}$ Figure 1 provides wounding time and site locations.

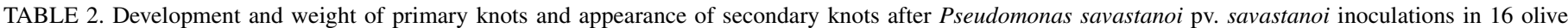
cultivars evaluated in experiment 1

\begin{tabular}{|c|c|c|c|c|c|}
\hline \multirow[b]{2}{*}{ Cultivar } & \multicolumn{2}{|c|}{$\begin{array}{c}\text { Percentage of primary knots } \\
\text { for } P \text {. savastanoi pv. savastanoi } \text { strains }^{\mathrm{w}}\end{array}$} & \multirow{2}{*}{$\begin{array}{c}\text { Weight of } \\
\text { primary knots }\end{array}$} & \multicolumn{2}{|c|}{$\begin{array}{c}\text { Percentage of secondary knots } \\
\text { for P. savastanoi pv. savastanoi strains }\end{array}$} \\
\hline & IVIA 1628 & IVIA $1657-8$ & & IVIA 1628 & IVIA $1657-8$ \\
\hline Arróniz & $100 \mathrm{a}$ & $81.8 \mathrm{ab}$ & $0.43 \mathrm{a}$ & $34.5 \mathrm{abc}$ & $68.2 \mathrm{abc}$ \\
\hline Changlot real & $100 \mathrm{a}$ & $90.9 \mathrm{a}$ & $0.41 \mathrm{a}$ & $32.7 \mathrm{abc}$ & $47.3 \mathrm{abc}$ \\
\hline Nevadillo blanco de Jaén-cj & $100 \mathrm{a}$ & $95.4 \mathrm{a}$ & $0.26 \mathrm{~b}$ & $50.0 \mathrm{abc}$ & $60.0 \mathrm{ab}$ \\
\hline Picudo & $100 \mathrm{a}$ & $100 \mathrm{a}$ & $0.31 \mathrm{~b}$ & n.d. ${ }^{z}$ & n.d. \\
\hline Arbequina & $97.7 \mathrm{a}$ & $100 \mathrm{a}$ & $0.43 \mathrm{a}$ & $86.0 \mathrm{a}$ & $56.3 \mathrm{abc}$ \\
\hline Morisca & $95.4 \mathrm{a}$ & $100 \mathrm{a}$ & $0.67 \mathrm{a}$ & $32.7 \mathrm{abc}$ & $24.0 \mathrm{bc}$ \\
\hline Lechín de Sevilla & $47.7 \mathrm{~b}$ & $68.2 \mathrm{ab}$ & $0.55 \mathrm{a}$ & $29.9 \mathrm{abc}$ & $43.6 \mathrm{abc}$ \\
\hline Oblonga & $38.6 \mathrm{bc}$ & $2.5 \mathrm{~d}$ & $0.19 \mathrm{~b}$ & $30.0 \mathrm{abc}$ & $4.0 \mathrm{bc}$ \\
\hline Gordal sevillana & $34.4 \mathrm{bc}$ & n.d. & $0.46 \mathrm{a}$ & $78.0 \mathrm{ab}$ & n.d. \\
\hline Frantoio & $6.8 \mathrm{~d}$ & $50.0 \mathrm{bc}$ & $0.19 \mathrm{~b}$ & $14.5 \mathrm{c}$ & $60.0 \mathrm{ab}$ \\
\hline Manzanilla cacereña & $6.8 \mathrm{~d}$ & $6.8 \mathrm{~d}$ & $0.17 \mathrm{~b}$ & $0.0 \mathrm{c}$ & $10.9 \mathrm{bc}$ \\
\hline Chemlali & $0.0 \mathrm{~d}$ & $0.0 \mathrm{~d}$ & n.d. & $1.8 \mathrm{c}$ & $0.0 \mathrm{c}$ \\
\hline Dulzal de Carmona & $0.0 \mathrm{~d}$ & $0.0 \mathrm{~d}$ & n.d. & $0.0 \mathrm{c}$ & $5.5 \mathrm{bc}$ \\
\hline Lechín de Granada & $0.0 \mathrm{~d}$ & $0.0 \mathrm{~d}$ & n.d. & $0.0 \mathrm{c}$ & $0.0 \mathrm{c}$ \\
\hline Picual & $0.0 \mathrm{~d}$ & $4.5 \mathrm{~d}$ & $0.05 \mathrm{~b}$ & $0.0 \mathrm{c}$ & $82.0 \mathrm{a}$ \\
\hline Villalonga & $0.0 \mathrm{~d}$ & $27.3 \mathrm{~cd}$ & $0.27 \mathrm{~b}$ & $0.0 \mathrm{c}$ & $38.2 \mathrm{abc}$ \\
\hline
\end{tabular}

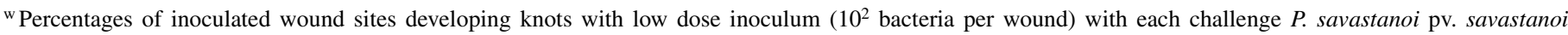
strain. Within each column, the different letters indicate significant differences based on a two-way generalized linear model $(P<0.0013)$.

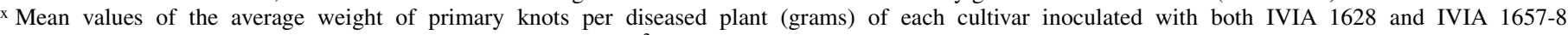
$P$. savastanoi pv. savastanoi strains with low inoculum dose $\left(10^{2}\right.$ bacteria per wound $)$. Cultivars with different letters vary significantly based on the DGC test $(P<0.05)$.

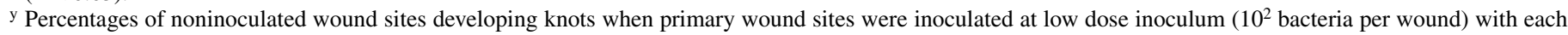
challenge $P$. savastanoi pv. savastanoi strain. Within each column, the different letters indicate significant differences based on a two-way generalized linear model $(P<0.0007)$.

z Not determined. 
Nevadillo blanco de Jaén-cj was rated as highly susceptible for production of primary knots in the first experiment when both $P$. savastanoi pv. savastanoi strains were used, and also in the second experiment only when strain IVIA 1657-8 was used.

TABLE 3. Development and weight of primary knots after Pseudomonas savastanoi pv. savastanoi inoculations in 25 olive cultivars evaluated in experiment 2

\begin{tabular}{|c|c|c|c|}
\hline \multirow[b]{2}{*}{ Cultivar } & \multicolumn{2}{|c|}{$\begin{array}{l}\text { Percentage of primary } \\
\text { knots for P. savastanoi } \\
\text { pv. savastanoi } \text { strain }^{\mathrm{y}}\end{array}$} & \multirow{2}{*}{$\begin{array}{c}\text { Weight of } \\
\text { primary knots }\end{array}$} \\
\hline & IVIA 1628 & IVIA $1657-8$ & \\
\hline Vallesa & $100.0 \mathrm{a}$ & 51.1 cde & $0.34 \mathrm{c}$ \\
\hline Royal de Cazorla & $90.9 \mathrm{a}$ & 32.7 cdef & $0.72 \mathrm{c}$ \\
\hline Ascolana tenera & $70.9 \mathrm{ab}$ & $7.3 \mathrm{f}$ & $0.27 \mathrm{c}$ \\
\hline Mollar de Cieza & $54.5 \mathrm{bc}$ & $21.8 \mathrm{def}$ & $0.87 \mathrm{c}$ \\
\hline Nevadillo blanco de Jaén-cj & $54.0 \mathrm{bcd}$ & $100.0 \mathrm{a}$ & $0.67 \mathrm{c}$ \\
\hline Gordal sevillana & 51.4 bcd & 35.0 cdef & $1.18 \mathrm{c}$ \\
\hline Pajarero & 50.9 bcde & $100.0 \mathrm{a}$ & $0.31 \mathrm{c}$ \\
\hline Changlot real & 40.0 bcdef & $0.0 \mathrm{f}$ & $0.18 \mathrm{c}$ \\
\hline Gordal de Hellín & $32.7 \mathrm{cdef}$ & $21.8 \mathrm{def}$ & $0.38 \mathrm{c}$ \\
\hline Lechín de Granada & 29.1 cdef & $14.5 \mathrm{f}$ & $0.08 \mathrm{c}$ \\
\hline Picual & 29.1 cdef & $78.2 \mathrm{ab}$ & $0.74 \mathrm{c}$ \\
\hline Nevadillo negro & 25.4 cdef & $14.5 \mathrm{f}$ & $0.07 \mathrm{c}$ \\
\hline Chemlali & 25.4 cdef & $9.1 \mathrm{f}$ & $0.45 \mathrm{c}$ \\
\hline Lechín de Sevilla & 21.8 cdef & $58.0 \mathrm{bc}$ & $0.26 \mathrm{c}$ \\
\hline Dulzal de Carmona & 20.0 cdef & $16.4 \mathrm{ef}$ & $0.13 \mathrm{c}$ \\
\hline Manzanilla cacereña & 20.0 cdef & 16.4 ef & $0.19 \mathrm{c}$ \\
\hline Cerezuela & $18.5 \mathrm{def}$ & $5.4 \mathrm{f}$ & $0.32 \mathrm{c}$ \\
\hline Frantoio & $16.4 \mathrm{ef}$ & 30.9 cdef & $2.91 \mathrm{a}$ \\
\hline Manzanilla de Sevilla & $16.4 \mathrm{ef}$ & $18.2 \mathrm{ef}$ & $0.09 \mathrm{c}$ \\
\hline Azapa & $7.3 \mathrm{f}$ & $18.2 \mathrm{ef}$ & $0.10 \mathrm{c}$ \\
\hline Morisca & $7.3 \mathrm{f}$ & $5.4 \mathrm{f}$ & $0.12 \mathrm{c}$ \\
\hline FS-17 & $0.0 \mathrm{f}$ & $0.0 \mathrm{f}$ & $0.00 \mathrm{c}$ \\
\hline Gordal de Archidona & $0.0 \mathrm{f}$ & $4.4 \mathrm{f}$ & $0.19 \mathrm{c}$ \\
\hline Koroneiki & $0.0 \mathrm{f}$ & 49.1 cde & $1.86 \mathrm{~b}$ \\
\hline Oblonga & $0.0 \mathrm{f}$ & $61.8 \mathrm{bc}$ & $1.47 \mathrm{~b}$ \\
\hline
\end{tabular}

y The inoculum dose was $10^{2}$ bacteria per wound. Within each column, different letters indicate significant differences based on a two-way generalized linear model $(P<0.0002)$.

${ }^{\mathrm{z}}$ Mean values of the average weight of primary knots per diseased plant (grams) of each cultivar inoculated with both IVIA 1628 and IVIA 1657-8 P. savastanoi pv. savastanoi strains at $10^{2}$ bacteria per wound. Weights followed by a different letter vary significantly based on the DGC test $(P<0.05)$.
Gordal sevillana, Oblonga, and Frantoio were rated for primary knots as medium and low in susceptibility depending on the experiment and $P$. savastanoi pv. savastanoi strain used. Chemlali, Dulzal de Carmona-cj, Lechín de Granada, and Manzanilla cacereña were rated as low susceptibility with respect to primary knot formation in both experiments with both $P$. savastanoi pv. savastanoi strains. Changlot real, Morisca, Lechín de Sevilla, and Picual varied greatly between experiments or strains used. Considering the weight of primary knots, 6 out of the 12 cultivars produced knots with a weight similar to that of the average weight in both experiments and were rated as medium in susceptibility. The other six cultivars produced knots with a greater weight than average, but only in one of the two experiments performed. With respect to the appearance of secondary knots, most of the cultivars were rated as medium or low in susceptibility to both $P$. savatanoi pv. savastanoi strains. Nevadillo blanco de Jaén-cj, Gordal sevillana, Frantoio, and Picual were rated as high but only when inoculated with one $P$. savastanoi pv. savastanoi strain.

Seventeen cultivars were analyzed just in one of the two performed experiments (Table 5). Considering the development of primary knots as the main factor to assess cultivar susceptibility after inoculations with $P$. savastanoi pv. savastanoi, in experiment 1, Arbequina, Arróniz, and Picudo were rated as having high susceptibility and Villalonga as having low susceptibility. For cultivars that were analyzed in experiment 2, Pajarero and Vallesa were classified as high or medium in susceptibility for primary knots depending on the strain used for inoculum. Mollar de Cieza and Koroneiki were classified as having medium or low susceptibility depending on the strain used. Azapa, Gordal de Hellín, FS-17, Nevadillo negro-cj, Cerezuela, Manzanilla sevillana, and Gordal de Archidona were classified as having low susceptibility for production of primary knots when inoculated with either $P$. savastanoi pv. savastanoi strain. Ascolana tenera and Royal de Cazorla were rated in different categories depending on the strain used for inoculum. Considering the weight of primary knots, all cultivars, except Arbequina, Arróniz, and Koroneiki, produced knots with a weight similar to that of the average. With respect to secondary knots, only cv. Arbequina was rated as highly susceptible in experiment 1 when inoculating strain IVIA 1628 .

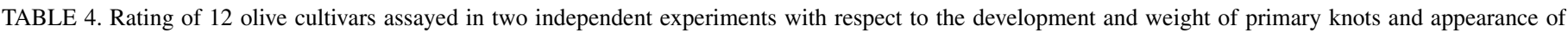
secondary knots after Pseudomonas savastanoi pv. savastanoi inoculations ${ }^{\mathrm{u}}$

\begin{tabular}{|c|c|c|c|c|c|c|c|c|c|}
\hline \multirow[b]{3}{*}{ Cultivar } & \multirow{3}{*}{$\begin{array}{c}\text { Reference } \\
\text { number }^{v}\end{array}$} & \multicolumn{4}{|c|}{ Susceptibility rating based on primary knots ${ }^{\mathrm{w}}$} & \multirow{2}{*}{\multicolumn{2}{|c|}{ Weight of primary knots ${ }^{x}$}} & \multirow{2}{*}{\multicolumn{2}{|c|}{$\begin{array}{c}\text { Susceptibility rating based } \\
\text { on secondary knots }{ }^{y}\end{array}$}} \\
\hline & & \multicolumn{2}{|c|}{ Experiment 1} & \multicolumn{2}{|c|}{ Experiment 2} & & & & \\
\hline & & IVIA 1628 & IVIA $1657-8$ & IVIA 1628 & IVIA $1657-8$ & Experiment 1 & Experiment 2 & IVIA 1628 & IVIA $1657-8$ \\
\hline Nevadillo blanco de Jaén-cj & $\mathrm{R}-44$ & $\mathrm{H}$ & $\mathrm{H}$ & M & $\mathrm{H}$ & M & M & M & $\mathrm{H}$ \\
\hline Changlot real & $\mathrm{R}-15$ & $\mathrm{H}$ & $\mathrm{H}$ & $\mathrm{L}$ & $\mathrm{L}$ & $\mathrm{H}$ & M & M & M \\
\hline Morisca & $\mathrm{R}-17$ & $\mathrm{H}$ & $\mathrm{H}$ & $\mathrm{L}$ & $\mathrm{L}$ & $\mathrm{H}$ & M & M & $\mathrm{L}$ \\
\hline Gordal sevillana & R-72 & M & n.d. ${ }^{\mathrm{z}}$ & M & $\mathrm{L}$ & $\mathrm{H}$ & M & $\mathrm{H}$ & n.d \\
\hline Lechín de Sevilla & $\mathrm{R}-5$ & M & $\mathrm{H}$ & $\mathrm{L}$ & M & $\mathrm{H}$ & M & M & $\mathrm{M}$ \\
\hline Oblonga & $\mathrm{R}-210$ & M & $\mathrm{L}$ & $\mathrm{L}$ & M & M & $\mathrm{H}$ & M & $\mathrm{L}$ \\
\hline Frantoio & $\mathrm{R}-80$ & $\mathrm{~L}$ & M & $\mathrm{L}$ & $\mathrm{L}$ & M & $\mathrm{H}$ & $\mathrm{L}$ & $\mathrm{H}$ \\
\hline Picual & R-9 & $\mathrm{L}$ & $\mathrm{L}$ & $\mathrm{L}$ & $\mathrm{H}$ & M & M & $\mathrm{L}$ & $\mathrm{H}$ \\
\hline Chemlali & R-744 & $\mathrm{L}$ & $\mathrm{L}$ & $\mathrm{L}$ & $\mathrm{L}$ & n.d. & M & $\mathrm{L}$ & $\mathrm{L}$ \\
\hline Dulzal de Carmona & R-31 & $\mathrm{L}$ & $\mathrm{L}$ & $\mathrm{L}$ & $\mathrm{L}$ & n.d. & M & $\mathrm{L}$ & $\mathrm{L}$ \\
\hline Lechín de Granada & R-54 & $\mathrm{L}$ & $\mathrm{L}$ & $\mathrm{L}$ & $\mathrm{L}$ & n.d. & M & $\mathrm{L}$ & $\mathrm{L}$ \\
\hline Manzanilla cacereña & $\mathrm{R}-430$ & $\mathrm{~L}$ & $\mathrm{~L}$ & $\mathrm{~L}$ & $\mathrm{~L}$ & $\mathrm{M}$ & M & $\mathrm{L}$ & $\mathrm{L}$ \\
\hline
\end{tabular}

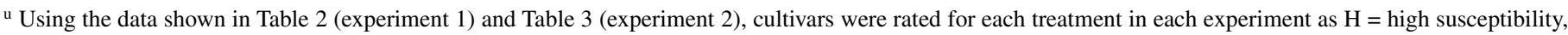
$\mathrm{M}=$ medium susceptibility, and $\mathrm{L}=$ low susceptibility as described in the text.

$v$ The registration number from the World Olive Germplasm Bank of CIFA, Córdoba, Spain, is indicated for each cultivar.

w Percentages of inoculated wound sites developing knots with low dose inoculum $\left(10^{2}\right.$ bacteria per wound) with each challenge $P$. savastanoi pv. savastanoi strain.

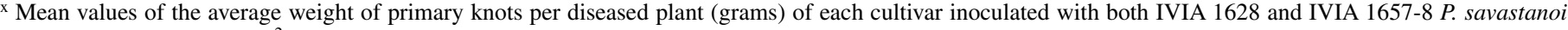
pv. savastanoi strains at $10^{2}$ bacteria per wound.

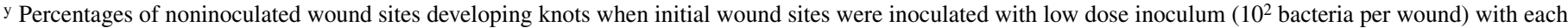
challenge $P$. savastanoi pv. savastanoi strain.

z Not determined. 


\section{DISCUSSION}

Information on the susceptibility of olive to olive knot disease is limited to few cultivars. Varvaro and Surico (23) compared the behavior of six Italian cultivars after P. savastanoi pv. savastanoi inoculation and did not find any differences because more than 95\% of the inoculated wound sites developed knots in all of them. Considering information obtained in the present study, their results were probably due to the high inoculum dose applied $\left(>10^{6}\right.$ bacteria per wound) and to the use of young plants (1-yearold). Benjama (3) inoculated six olive cultivars from Italy, Morocco, and Spain with eight $P$. savastanoi pv. savastanoi strains at different doses. Although, he did not report any statistical analysis of the data, he concluded that cv. Gordal sevillana was more tolerant to olive knot disease than the other cultivars. Marcelo et al. (11) evaluated six Portuguese cultivars by inoculating with only one $P$. savastanoi pv. savastanoi strain and found slight differences among cultivars. The percentage of inoculated sites with knots ranged from 36 to $66 \%$ depending on the cultivar, but the results were not statistically analyzed. Finally, Hassani et al. (9) evaluated five Italian cultivars inoculated with five $P$. savastanoi pv. savastanoi strains at an inoculum dose of ca. $5 \times$ $10^{7}$ bacteria per wound. Although they did not report the percentage of inoculated wound sites that developed knots, it is likely that with the high inoculum dose used, more than $90 \%$ of wounds developed knots in all cultivars. Consequently, they evaluated cultivars only by determining the knot size with a visual scale. As far as we know, no more information on this subject is available.

Our data from $P$. savastanoi pv. savastanoi virulence assays suggested that most of the analyzed strains of $P$. savastanoi pv. savastanoi were highly virulent on olive plants. Two strains were used as challenge pathogens in cultivar susceptibility to indicate the possibility of interactions between a given strain of the pathogen and a given cultivar and to minimize the error in cultivar evaluation due to interactions. Pathogen-cultivar interactions were inferred from previous $P$. savastanoi pv. savastanoi inoculation experiments (3). Our results from dose/response assays with three cultivars indicate that the disease response was strongly dependent on the inoculum dose applied to the wounds, and confirm previous data indicating that inoculation with more than $10^{4}$ to $10^{5}$ bacteria per wound obscures differences between cultivars, because more than $75 \%$ of inoculated wound sites developed knots regardless of the cultivar $(3,23)$. The fact that small differences in the inoculum dose resulted in big differences in the disease response for the same cultivar might explain possible discrepancies among cultivar evaluation from different sources. We found that an inoculum dose of $10^{2} \mathrm{CFU} /$ wound was the most appropriate for assaying cultivar susceptibility. We also determined that young olive plants (1-year-old) were too susceptible to olive knot disease for discrimination of susceptibility among cultivars. Probably, low susceptible phenotypes are only expressed in olive plants after a certain period of time or vegetative development.

Our data support the concept that $P$. savastanoi pv. savastano is able to migrate and produce secondary knots in new wounds in olive plants as suggested earlier $(20,24)$. Similar development of secondary tumors following migration of $P$. savastanoi pv. savastanoi from the site of inoculation in oleander stems has been reported (25). In the present study, a correlation between the number of inoculated sites developing knots and the number of secondary knots that appeared in noninoculated wound sites was found when inoculating the primary wounds with a low inoculum dose. In nature it is frequent to observe new knots mainly in branches already harboring old knots. Our data suggest that evaluation of this trait might be useful in determining cultivar susceptibility.

In summary, based on the results of our study, we propose for evaluation of olive cultivars to olive knot disease take into account the development of primary knots after application of a low inoculum dose of two $P$. savastanoi pv. savastanoi strains. Using this method, most cultivars were clearly placed into three susceptibility categories; however, a few of the cultivars varied greatly in

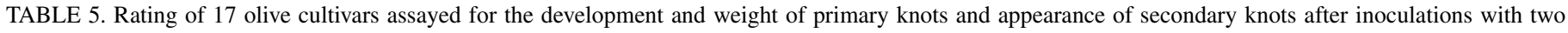
Pseudomonas savastanoi pv. savastanoi strains in a unique experiment ${ }^{\mathrm{s}}$

\begin{tabular}{|c|c|c|c|c|c|c|c|}
\hline \multirow[b]{2}{*}{ Cultivar } & \multirow{2}{*}{$\begin{array}{c}\text { Reference } \\
\text { number }^{\mathrm{t}}\end{array}$} & \multirow[b]{2}{*}{ Experiment } & \multicolumn{2}{|c|}{$\begin{array}{l}\text { Susceptibility rating based } \\
\text { on primary knots }{ }^{\mathrm{u}}\end{array}$} & \multirow{2}{*}{$\begin{array}{c}\text { Weight of } \\
\text { primary knots }^{\mathrm{v}}\end{array}$} & \multicolumn{2}{|c|}{$\begin{array}{l}\text { Susceptibility rating based } \\
\text { on secondary knots }{ }^{\mathrm{w}}\end{array}$} \\
\hline & & & Strain IVIA 1628 & Strain IVIA $1657-8$ & & Strain IVIA 1628 & Strain IVIA $1657-8$ \\
\hline Arbequina & $\mathrm{R}-231$ & 1 & $\mathrm{H}$ & $\mathrm{H}$ & $\mathrm{H}$ & $\mathrm{H}$ & M \\
\hline Arróniz & $--^{\mathrm{x}}$ & 1 & $\mathrm{H}$ & $\mathrm{H}$ & $\mathrm{H}$ & M & $\mathrm{M}$ \\
\hline Picudo & R-314 & 1 & $\mathrm{H}$ & $\mathrm{H}$ & M & n.d. ${ }^{y}$ & n.d. \\
\hline Villalonga & $\mathrm{R}-364$ & 1 & $\mathrm{~L}$ & $\mathrm{~L}$ & M & $\mathrm{L}$ & $\mathrm{M}$ \\
\hline Pajarero & $\mathrm{R}-26$ & 2 & M & $\mathrm{H}$ & M & & \\
\hline Vallesa & $\mathrm{R}-613$ & 2 & $\mathrm{H}$ & M & M & & \\
\hline Ascolana tenera & R-62 & 2 & $\mathrm{H}$ & $\mathrm{L}$ & M & & \\
\hline Royal de Cazorla & R-390 & 2 & $\mathrm{H}$ & $\mathrm{L}$ & M & & \\
\hline Mollar de Cieza & R-544 & 2 & M & $\mathrm{L}$ & M & & \\
\hline Koroneiki & $-^{\mathrm{Z}}$ & 2 & $\mathrm{~L}$ & M & $\mathrm{H}$ & & \\
\hline Azapa & $\mathrm{R}-726$ & 2 & $\mathrm{~L}$ & $\mathrm{~L}$ & M & & \\
\hline Gordal de Hellín & $R-567$ & 2 & $\mathrm{~L}$ & $\mathrm{~L}$ & M & & \\
\hline FS-17 & $--^{\mathrm{z}}$ & 2 & $\mathrm{~L}$ & $\mathrm{~L}$ & M & & \\
\hline Nevadillo negro-cj & $\mathrm{R}-45$ & 2 & $\mathrm{~L}$ & $\mathrm{~L}$ & M & & \\
\hline Cerezuela & $\mathrm{R}-331$ & 2 & $\mathrm{~L}$ & $\mathrm{~L}$ & M & & \\
\hline Manzanilla de Sevilla & $\mathrm{R}-21$ & 2 & $\mathrm{~L}$ & $\mathrm{~L}$ & M & & \\
\hline Gordal de Archidona & $\mathrm{R}-755$ & 2 & $\mathrm{~L}$ & $\mathrm{~L}$ & M & & \\
\hline
\end{tabular}

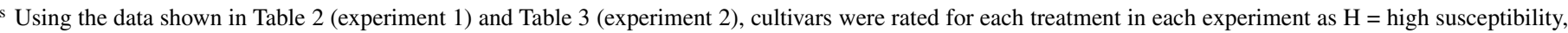
$\mathrm{M}=$ medium susceptibility, and $\mathrm{L}=$ low susceptibility as described in the text.

t The registration number from the World Olive Germplasm Bank of CIFA, Córdoba, Spain, is indicated for each cultivar.

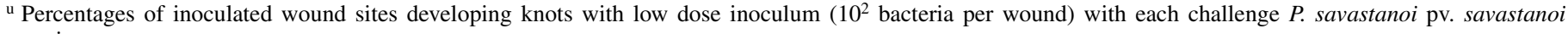
strain.

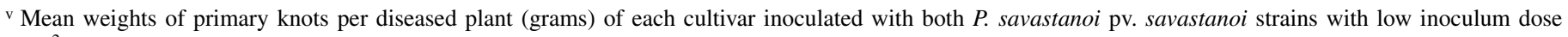
$\left(10^{2}\right.$ bacteria per wound $)$.

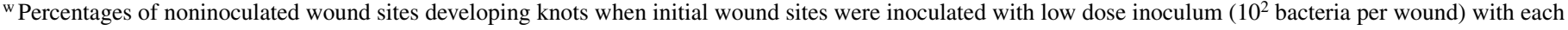
challenge $P$. savastanoi pv. savastanoi strain in experiment 1.

$x$ This cultivar was supplied by B. Lizar from ITGA, Navarra, Spain.

y Not determined.

z These cultivars were supplied by J. Pinochet from Agromillora Catalana, S.A., Barcelona, Spain. 
their behavior, and could not be definitively classified in any one category. Weight of primary knots and the presence of secondary knots can be considered as secondary factors when assessing cultivar susceptibility to olive knot disease. We propose that the method can be used in further olive cultivar susceptibility assays. Based on our data, we suggest the following cultivars from the World Olive Germplasm Bank of CIFA, Spain, can be used as controls in further cultivar susceptibility analyses: Nevadillo blanco de Jaén-cj R-44 or Picudo R-314 can be considered as highly susceptible cultivars, and Dulzal de Carmona-cj R-31, Lechín de Granada R-54, or Manzanilla cacereña R-430 as low susceptible cultivars.

\section{ACKNOWLEDGMENTS}

This work was supported in part by grants OLI96-2179 from CICYT and CAO00-007 from INIA, and by grant GRUPOS03/221 from Generalitat Valenciana, Spain. J. M. Quesada has a predoctoral fellowship from I.F.A.P.A, Andalucía, Spain. R. Penyalver and C. del Río have a contract from the Ministerio de Ciencia y Tecnología of Spain (Programas Ramón y Cajal and INIA/CC.AA., respectively). We thank R. González, J. Peñalver, and C. Morente for helping us in plant inoculations; I. Lorite and D. Hidalgo for assistance in propagating and training plants; B. Lizar and J. Pinochet for providing us with some olive cultivars; and C. Ramos for critical reading of the manuscript.

\section{LITERATURE CITED}

1. Alarcón De La Lastra, C., Barranco, M. D., Motilva, V., and Herrerias, J. M. 2001. Mediterranean diet and health: Biological importance of olive oil. Curr. Pharm. Des. 7:933-950.

2. Barranco, D. 1997. Variedades y patrones. Pages 59-79 in: El Cultivo del Olivo. Mundi-Prensa, Madrid, Spain.

3. Benjama, A. 1994. Étude de la sensibilité variétale de l'olivier au Maroc vis-à-vis de Pseudomonas syringae pv. savastanoi, agent de la tuberculose. Cahiers Agric. 3:405-408.

4. Caballero, J. M., and del Río, C. 2001. Métodos de multiplicación. Pages 91117 in: El Cultivo del Olivo, 4th ed. D. Barranco, D. Fernández Escobar, and L. Rallo, eds. Junta de Andalucía/Mundi-Prensa, Madrid, Spain.

5. Comai, L., and Kosuge, T. 1980. Involvement of plasmid deoxyribonucleic acid in indoleacetic acid synthesis in Pseudomonas savastanoi. J. Bacteriol. 143:950-957.

6. del Rio, C., and Caballero, J. M. 1994. Preliminary agronomical characterization of 131 cultivars introduced in the olive germplasm bank of Córdoba in March 1987. Acta Hortic. 356:110-115.

7. del Río, C., and Proubi, A. 1999. Training initiation date affects height of nursery olive trees. HortTechnology 9:482-485.
8. DiRienzo, J. A., Guzmán, A. W., and Casanoves, F. 2002. A multiple comparisons method based on the distribution of the root node distance of a binary tree. J. Agric. Biol. Environ. Stat. 7:1-14.

9. Hassani, D., Buonaurio, R., and Tombesi, A. 2003. Response of some olive cultivars, hybrid and open pollinated seedling to Pseudomonas savastanoi pv. savastanoi. Pages 489-494 in: Pseudomonas syringae and Related Pathogens. Kluwer Academic Publishers, the Netherlands.

10. King, E., Ward, O., and Raney, D. E. 1954. Two simple media for the demonstration of pyocyanin and fluorescein. J. Lab. Clin. Med. 44:301307.

11. Marcelo, A., Fernandes, M., Fatima Potes, M., and Serrano, J. F. 1999. Reactions of some cultivars of Olea europaea L. to experimental inoculation with Pseudomonas syringae pv. savastanoi. Acta Hortic. 474:581-584.

12. McCullagh, P., and Nelder, J. A. 1989. Generalized Linear Models. 2nd ed. Chapman and Hall, London, UK.

13. Nester, E. W., and Kosuge, T. 1981. Plasmids specifying plant hyperplasias. Annu. Rev. Microbiol. 35:531-565.

14. Owen, R. W., Giacosa, A., Hull, W. E., Haubner, R., Wurtele, G., Spiegelhalder, B., and Bartsch, H. 2000. Olive-oil consumption and health: The possible role of antioxidants. Lancet Oncol. 1:107-112.

15. Schroth, M. N., Hildebrand, D. C., and O'Reilly, H. J. 1968. Off-flavor of olives from trees with olive knot tumors. Phytopathology 58:524-525.

16. Schroth, M. N., Osgood, J. W., and Miller, T. D. 1973. Quantitative assessment of the effect of the olive knot disease on olive yield and quality. Phytopathology 63:1064-1065.

17. Sisto, A., Cipriani, M. G., and Morea, M. 2004. Knot formation caused by Pseudomonas savastanoi subsp. savastanoi on olive plants is hrpdependent. Phytopathology 94:484-489.

18. Sisto, A., and Iacobellis, N. S. 1999. La "Rogna dell'olivo": Aspetti patogenetici, epidemiologici e strategie di lotta. Olivo Olio 12:32-38.

19. Smidt, M., and Kosuge, T. 1978. The role of indole-3-acetic acid accumulation by alpha-methyl tryptophan-resistant mutants of Pseudomonas savastanoi in gall formation in oleander. Physiol. Plant Pathol. 13:203214.

20. Smith, E. F. 1920. Bacterial Diseases of Plants. W. B. Saunders Company, Philadelphia.

21. Surico, G., Iacobelis, N. S., and Sisto, S. 1985. Studies on the role of indole-3-acetic acid and cytokinins in the formation of knots on olive and oleander plants by Pseudomonas syringae pv. savastanoi. Physiol. Plant Pathol. 26:309-320.

22. Trapero, A., and Blanco, M. A. 1997. Enfermedades. Pages 461-507 in: El Cultivo del Olivo. Mundi-Prensa, Madrid, Spain.

23. Varvaro, L., and Surico, G. 1978. Comportamento di diverse cultivars di Olivo (Olea europaea L.) alla inoculazione artificiale con Pseudomonas savastanoi (E. F. Smith) Stevens. Phytopathol. Mediterr. 17:174-178.

24. Wilson, E. E. 1935. The olive knot disease: Its inception, development, and control. Hilgardia 9:231-264.

25. Wilson, E. E., and Maggie, A. R. 1964. Systemic invasion of the host plant by the tumor-inducing bacterium, Pseudomonas savastanoi. Phytopathology 54:576-579. 